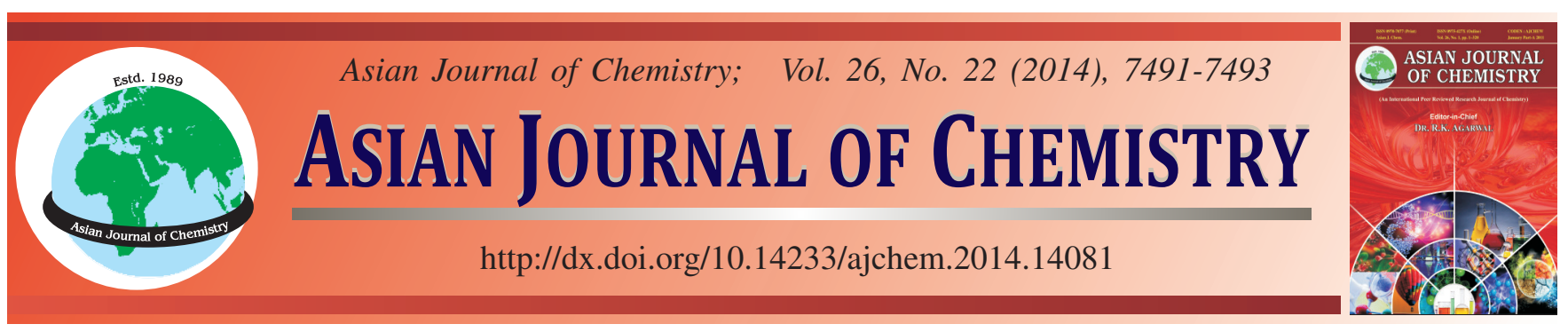

\title{
Aptamer-Based Fluorescence Polarimetric Assay for the Sensitive Detection of Immunoglobulin E in Human Serum
}

\author{
XIAOHUAN QIN
}

Key Laboratory for the Chemistry and Molecular Engineering of Medi cinal Resources (Ministry of Education of China), School of Chemistry and Chemical Engineering of Guangxi Normal University, Guilin 541004, P.R. China

Corresponding author: Tel/Fax: +86 773 2120958; E-mail: qinchengshi091129@163.com

\begin{abstract}
A highly sensitive and selective fluorescence polarization method was developed for the determination of immunoglobulin E based on the aptamer specificity binding immunoglobulin E event into a detectable fluorescence polarization signal. Using this method, the levels of immunoglobulin E in human serum from healthy donors were determined. The results show that the fluorescence polarization method has excellent specificity against target protein and high sensitivity in complex medium and is applicable to the no-separation based detection of proteins in biological sample.
\end{abstract}

Keywords: Immunoglobulin E, Fluorescence polarization, Aptamer.

\section{INTRODUCTION}

Immunoglobulin $\mathrm{E}$ is the immunoglobulin component only found in mammals, its amount is especially small in human blood serum. And it is capable of result from the most powerful immune reactions ${ }^{1}$. The immunoglobulin E plays a key role in allergic responses, which causing hergthened researchers' interest and research into the mechanisms of type-1 hypersensitivity ${ }^{2}$. And its amount increases in patients afflicated with allergic asthma, atopic dermatitis and other immune deficiency-related disease, such as $\operatorname{AIDS}^{3,4}$. So, it is important to develop a simple and rapid detection method for immunoglobulin E with high sensitive and selective in clinical diagnostics. Traditionally quantitative analysis proteins method in blood serum including autoradiography, enzyme-linked immunosorbent assay (ELISA) and western blotting. In these methods, antibodies are the most common reagent. However, antibodies were found shortcoming in research process, such as their temperature-sensitive feature and specific reaction conditions as well as the need for a secondary antibody conjugated to an enzyme and a fluorescent dye. To overcome these drawbacks, aptamers as a substitute for antibody were used to biosensors for the detection and measurement biosample or environmental molecules ${ }^{5}$. Aptamers are single-stranded RNA or DNA oligonucleotides and screened by systematic evolution of ligands by exponential enrichment (SELEX) which offer highly affinity and specific selectivity to a variety of targets, including small molecular ${ }^{6,7}$, metal ions, DNA and protein ${ }^{8,9}$. The specific oligonucleotide aptamer that binds to immunoglobulin $\mathrm{E}$ with high affinity has been elucidated by mass spectrum $^{10}$, atomic force microscopy ${ }^{11}$, capillary electrophoresis $^{12}$, electrochemiluminescence ${ }^{13}$, electrochemical ${ }^{14}$, and biochip $^{15}$, However, these methods are time-consuming, separation and laborious.

Herein we report a highly sensitive and selective fluorescence polarization assay (FPA) method for detection immunoglobulin E by aptamer specificity binding immunoglobulin E event into a detectable fluorescence polarization signal. Aptamer-based fluorescence polarization detection have been employed to quantitative analysis of molecular interactions ${ }^{16,17}$, determine biomarker ${ }^{18,19}$ and metal ion ${ }^{20}$, endonuclease activity and inhibition screening ${ }^{21}$. The polarization value $(\mathrm{P})$ can be calculated by the Perrin equation ${ }^{20}$, which in turn depend upon their molecular volume (molecular weight) at constant temperature and solution viscosity. In this works, we aimed to combine the advantages of aptamer and fluorescence polarization assay to develop a method for immunoglobulin E. The fluorescence polarization value $(\mathrm{P})$ of the aptasensor solution is large due to the enlargement of molecular volume of the protein-DNAFITC complexes with slow rotation. Therefore, the immunoglobulin E concentrations can be quantified by monitoring the change in the P value. It is a simple and ideal method for real time protein signaling in homogeneous solution without the need for any separation. 
EXPERIMENTAL

The DNA oligonucleotides, including fluorescein isothiocyanate (FITC) -labeled 37-nt immunoglobulin E DNA aptamer 5'(FITC)-GGGGCACGTTTATCCGTCCCTCCT AGTG-GCGTGCCCC-3' and a scrambled control sequence 5'(FITC)-ATATGTCAGT GATTGAGTTAATTATAATAT were synthesized and high performance liquid chromatography (HPLC) purified by Sangon Biotech Co., Ltd. (shanghai, China). Immunoglobulin $\mathrm{E}$, human immunoglobulin $\mathrm{G}(\mathrm{IgG})$ and human serum albumin (HSA) were obtained from Sigma Aldrich. NaCl, $\mathrm{KCl}, \mathrm{MgCl}_{2}$ and salt phosphate was obtained from Guangzhou Chemical Reagent (Guangzhou, China). Milli-Q water was used throughout. The solutions were prepared by diluting the appropriate volume of the commercial sample in buffer (10 $\mathrm{mM}$ sodium phosphate buffer containing $3 \mathrm{mM} \mathrm{KCl}$ and 1 $\mathrm{mM} \mathrm{MgCl} 2, \mathrm{pH} 7.4$ ) and stored at $4{ }^{\circ} \mathrm{C}$. All the other chemicals used in this work were of analytical grade. Steady-state fluorescence experiments were all performed using a Time-resolved fluorescence spectrometer (HORIBA JOBIN JVON, France).

Fluorescence polarization measurements: A $10 \mu \mathrm{L}$ aptamer probe and a certain amount of immunoglobulin $\mathrm{E}$ or control proteins were added into centrifuge tube and then diluted to $1 \mathrm{~mL}$ with buffer. Subsequently the solutions were incubated for $0.5 \mathrm{~h}$ at $37^{\circ} \mathrm{C}$. The final concentration of aptamer was $10 \mathrm{nM}$. Finally, Excitation was set at $491 \mathrm{~nm}$ and emission was collected with $517 \mathrm{~nm}$.

\section{RESULTS AND DISCUSSION}

Selectivity studies: To validate the interaction between aptasensor and immunoglobulin E molecule with high affinity and selectivity, the assay was explored by monitoring the response of fluorescence polarization toward the other protein including human immunoglobulin $\mathrm{G}$ and human serum albumin at a concentration $600 \mathrm{ng} / \mathrm{mL}$. The experimental results of the interferences were shown in Fig. 1. The fluorescence polarization aptasensor response to target protein was higher than the control protein. The polarization values almost keep immovability in the presence of these control protein. The specific detection for immunoglobulin $\mathrm{E}$ was due to the high affinity of the aptasensor to immunoglobulin E. The results clearly showed that this proposed method have high selectivity for immunoglobulin E over the other protein.

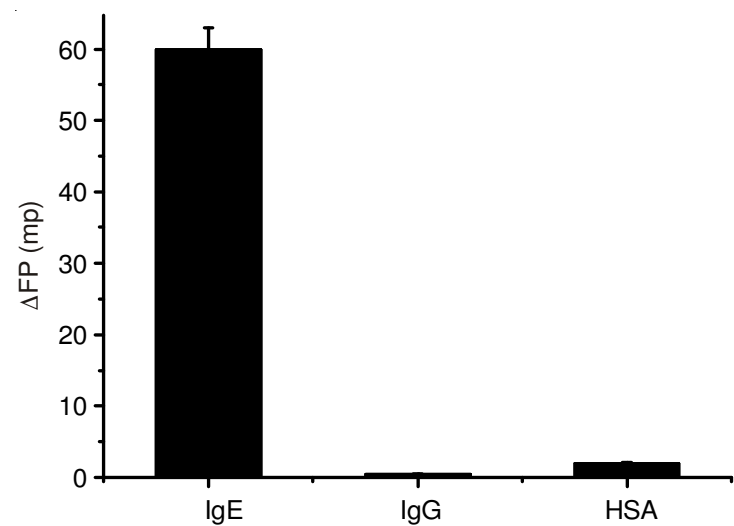

Fig. 1. Selectivity of the immunoglobulin E assay method. The concentration of immunoglobulin E was $200 \mathrm{ng} / \mathrm{mL}$, the other proteins were tested at $600 \mathrm{ng} / \mathrm{mL}$. Aptamer probe concentration $=10 \mathrm{nM}$. immunoglobulin $\mathrm{E}(\mathrm{IgE})$ concentration $=40 \mathrm{ng} / \mathrm{mL}$
In order to further prove that this behaviour resulted from the immunoglobulin E aptamer and immunoglobulin E, the scrambled control sequence DNA was tested under the same experimental conditions as in the case of immunoglobulin $\mathrm{E}$ aptamer (Fig. 2). The concentration of immunoglobulin E, immunoglobulin $\mathrm{G}$ and human serum albumin vary from 0.0 to $1000 \mathrm{ng} / \mathrm{mL}$. The results indicated that no fluorescence polarization change was observed in the presence of scambled control sequence DNA. Therefore, these results directly confirmed that the interaction between the aptamer sensor and immunoglobulin $\mathrm{E}$ had a sufficient affinity specificity and high selectivity. The selectivity tested for immunoglobulin $\mathrm{E}$ was attributed mainly its ability of specific interaction between aptamer probe and target of immunoglobulin $\mathrm{E}$.

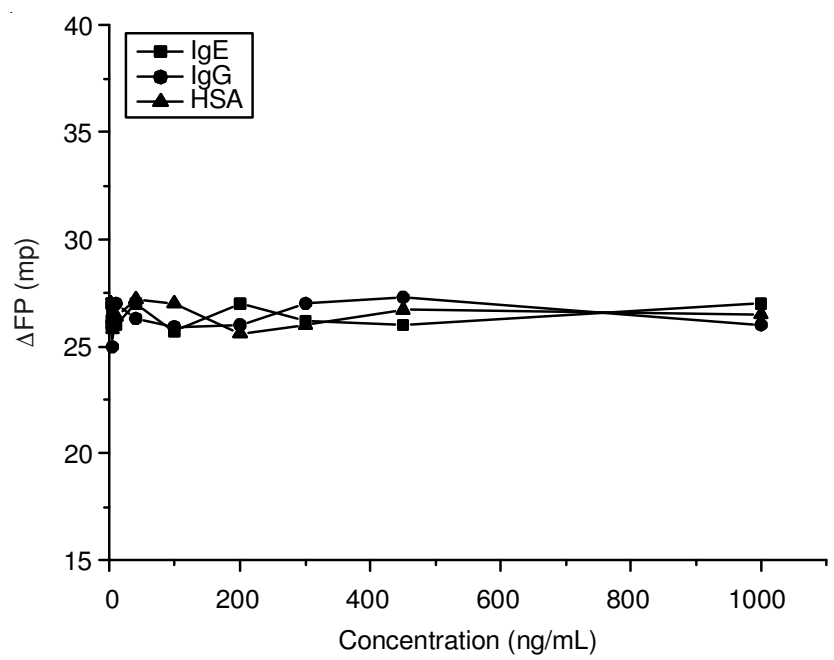

Fig. 2. Fluorescence polarization respond curve of scrambled sequence DNA to immunoglobulin E (IgE), HSA and IgG solution. The concentration of scrambled sequence DNA was $10 \mathrm{nM}$. The other conditions were as in Fig. 1

Analytical applications: This method can be used for sensitive quantification of target protein, the fluorescence polarization values of complex were determined at different concentration immunoglobulin E from the same stock solution. The calibration curve was shown in Fig. 3. One can observe that the current analytical signal of fluorescence polarization increased as the concentration of immunoglobulin E increased. And the calibration curve showed good linearity range from 4 to $200 \mathrm{ng} / \mathrm{mL}$ for immunoglobulin $\mathrm{E}$ (Inset in Fig. 3). The linear regression equation was fluorescence polarization ( $\mathrm{mp}$ ) $=0.2874 \mathrm{C}+3.5319$ (where $\mathrm{C}$ is immunoglobulin E concentration) with a correlation coefficient of 0.9984 . The fluorescence polarization was repeatedly determined for three times.

To test if this protocol method developed here was applicable to practical sample. Human serum samples from four adult healthy volunteers were analyzed. $100 \mu \mathrm{L}$ serum was used to detect immunoglobulin E content according to the procedure under optimum conditions. The analytical results were summarized in Table-1. The concentration of immunoglobulin $\mathrm{E}$ in human serum were found to be in the range of 263.5-841.2 ng/mL. These results were in accordance with those obtained by the capillary electrophoresis method ${ }^{12}$. The precision of the detection results were evaluated by repeatedly 


\begin{tabular}{cccccc}
\hline \multicolumn{7}{c}{ TABLE-1 } \\
& \multicolumn{7}{c}{ DETERMINATION RESULTS OF IMMUNOGLOBULIN E IN HUMAN SERUM SAMPLES } \\
\hline Sample & Found $(\mathrm{ng} / \mathrm{mL})$ & RSD $(\%, \mathrm{n}=5)$ & Added $(\mathrm{ng} / \mathrm{mL})$ & Total found $(\mathrm{ng} / \mathrm{mL})$ & Recovery $(\%)$ \\
\hline 1 & 634.4 & 3.3 & 600.0 & 1225.4 & 98.5 \\
2 & 263.5 & 2.6 & 300.0 & 545.2 & 93.9 \\
3 & 841.2 & 1.9 & 800.0 & 1618.8 & 97.2 \\
4 & 396.0 & 4.5 & 400.0 & 798.4 & 100.6 \\
\hline
\end{tabular}

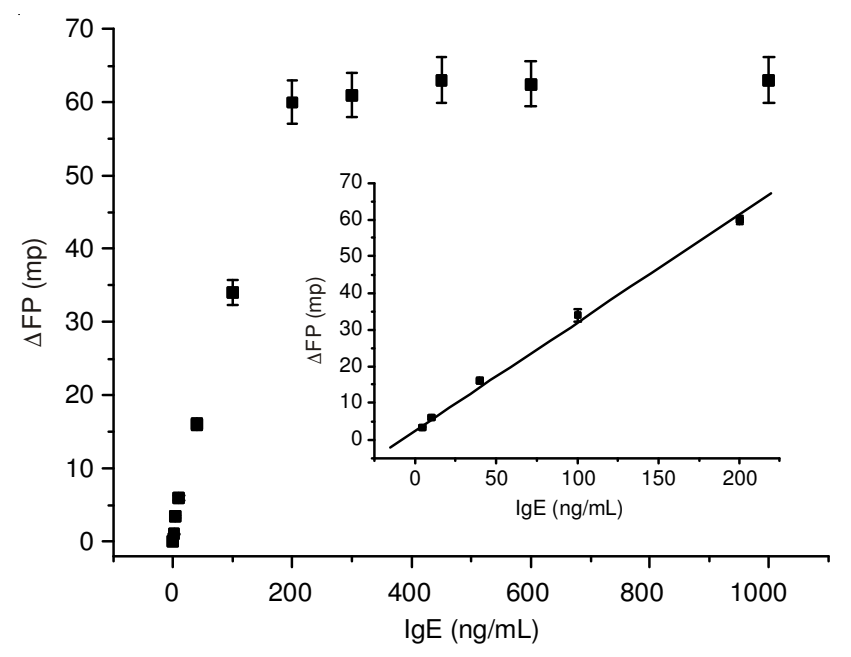

Fig. 3. Fluorescence polarization respond curve of aptamer probe to immunoglobulin E solution. Inset: the calibration plots of immunoglobulin E (IgE). The other conditions were as in Fig. 1

analyzing each human serum sample five times within one working day. The relative standard deviation (RSD) was $4.5 \%$. The various concentration of immunoglobulin $\mathrm{E}$ was added to study recoveries of immunoglobulin $\mathrm{E}$ from these serum samples. The recoveries were found to be in the range of 93.9 to $100.6 \%$. The results indicated that the proposed system had good reliability to determine practical assay.

\section{Conclusion}

In summary, a simple, rapid, highly selectivity and sensitivity fluourescence aptamer biosenor was found to be suitable for determination of immunoglobulin $\mathrm{E}$ in human serum through fluorescence polarization strategy. Control experiment was carried out and the results to confirmed the binding between aptamer and target protein has highly specific affinity and selectivity. The analytical results of human serum were in accordance with those obtained by the HPCE method. It was worth to mention that the approach have on required anything separation steps in the whole blood serum assay. These advan- tages showed that aptamer-based fluorescence polarization method had a potential application for the biomedical analysis.

\section{ACKNOWLEDGEMENTS}

The authors gratefully acknowledge the Foundation of Key Laboratory for Chemistry and Molecular Engineering of Medicinal Resources (Guangxi Normal University), Ministry of Education of China (CMEMR2013-A11).

\section{REFERENCES}

1. B.J. Sutton and H.J. Gould, Nature, 366, 421 (1993).

2. J.V. Ravetch and J.P. Kinet, Annu. Rev. Immunol., 9, 457 (1991).

3. C.A. DeWitt, A.B. Bishop, L.S. Buescher and S.P. Stone, Am. Acad. Dermatol., 54, 855 (2006).

4. C. Rancinan, P. Morlat, G. Chêne, S. Guez, A. Baquey, J. Beylot and R. Salamon, J. Allergy Clin. Immunol., 102, 329 (1998).

5. S.D. Jayasena, Clin. Chem., 45, 1628 (1999).

6. D.D. Nie, H.Y. Wu, Q.S. Zheng, L.Q. Guo, P.R. Ye, Y.L. Hao, Y.N. Li, F.F. Fu and Y.H. Guo, Chem. Commun., 48, 1150 (2012).

7. Y.Q. Wen, F.F. Xing, S.J. He, S.P. Song, L.H. Wang, Y.T. Long, D. Li and C.H. Fan, Chem. Commun., 46, 2596 (2010).

8. Z.Z. Zhang and C.Y. Zhang, Anal. Chem., 84, 1623 (2012).

9. D. Rotem, L. Jayasinghe, M. Salichou and H. Bayley, J. Am. Chem. Soc., 134, 2781 (2012).

10. J.R. Cole, L.W. Dick, J.E.J. Morgan and L.B. McGown, Anal. Chem., 79, 273 (2007).

11. Y.X. Jiang, C.F. Zhu, L.S. Ling, L.J. Wan, X.H. Fang and C.L. Bai, Anal. Chem., 75, 2112 (2003).

12. I. German, D.D. Buchanan and R.T. Kennedy, Anal. Chem., 70, 4540 (1998).

13. Y.S. Guo, X. Jia and S. Zhang, Chem. Commun., 47, 725 (2010).

14. Z.S. Wu, F. Zheng, G.L. Shen and R.Q. Yu, Biomaterials, 30, 2950 (2009).

15. K. Stadtherr, H. Wolf and P. Lindner, Anal. Chem., 77, 3437 (2005).

16. D.M. Jameson and S.E. Seifried, Methods, 19, 222 (1999).

17. J.R. Lundblad, M. Laurance and R.H. Goodman, Mol. Endocrinol., 10, 607 (1996).

18. J. Ruta, S. Perrier, C. Ravelet, J. Fize and E. Peyrin, Anal. Chem., 81, 7468 (2009).

19. M. Zhang, Y.M. Guan and B.C. Ye, Chem. Commun., 47, 3478 (2011).

20. B.C. Ye and B.C. Yin, Angew. Chem. Int. Ed., 47, 8386 (2008).

21. Y. Huang, S.L. Zhao, Z.F. Chen, Y.C. Liu and H. Liang, Chem. Commun., 47, 4763 (2011). 